\title{
Increasing the motivation of the students to learn mathematics
}

\author{
Zoran Trifunov \\ PhD Associate Professor, Faculty of Technical Sciences, Mother Teresa University, \\ 1000 Skopje, Republic of Macedonia
}

\begin{abstract}
The students use computers, smartphones and other electronic devices everyday for their own needs. The success in Mathematics is getting lower and lower, both on local level in Macedonia and on global level also [6]. A lot of the students are having difficulties with learning Mathematics, and with that also the motivation for learning Mathematics decreases. The difficulties are shown in both, mastering the material in school and solving the exercises at home. Also, when the students solve reallife problems, they are not connecting what was learned on Mathematics classes with those problems. They almost don't use the Mathematics and the electronic devices at all for solving the real-life problems. If we succeed in encouraging the students in using these electronical devices and softwares for: examining, investigating, visualizing and solving reallife problems, we will get students that are motivated for learning mathematics, and with that also we will get increased level of knowledge of mathematics.

In this project, for increasing the motivation for learning mathematics and increasing the level of knowledge, we made a web application http://mathlabyrinth.azurewebsites.net

The problems that are put on the web application are connected with real-life problems the students have, who need knowledge from secondary education mathematics to solve them.
\end{abstract}

Keywords - mathematics, motivation, web application, exercise, IT.

\section{INTRODUCTION}

In several latest researches that have been done in our country, and wider, it has been established that the knowledge in mathematics and the pupils' motivation for studying mathematics are reduced and they are below the minimum level of knowledge. Thus, one of the priorities of our country and wider in the field of education is to motivate the pupils to study mathematics and to increase the level of knowledge in the same subject with the pupils of all ages.

How to increase the level of knowledge in mathematics and how to increase the motivation for studying mathematics?

Because the pupils use computers, smart phones and other electronic devices for their needs more and more, there is a need to incorporate them in the education and in the studying of mathematics. The free software (GeoGebra) is used in the teaching, which is used to solve and visualize the constructive exercises [1], exercises with functions, exercises from plane geometry and solid geometry, exercises with probability [7] and others. Using the software class marker there have been made electronic tests to test the pupils' knowledge [2], which are quite positively accepted by them. However, IT is not used enough in the teaching and it is still necessary to work on raising the pupils`motivation and their level of knowledge.

In order to establish the benefits of the use of the web application in teaching mathematics and increasing the motivation, and by doing that increasing the knowledge in mathematics too, two surveys have been made with the pupils of the Gymnasium "Kocho Racin" from Veles. One before beginning with the use of the web application in the teaching of mathematics, and the other after one year usage of the web application.

146 pupils participated in the first survey. The accent of this survey is put on solving textual exercises in which the problems of the real life are elaborated, using the IT while solving them, solving the exercises in domestic conditions (home work) and motivation for studying mathematics [3].

Some of the questions from the first survey, before beginning with the use of the project and given answers:

- To the question "Do you think that you can increase the motivation for studying mathematics by solving practical exercises" $67 \%$ of the pupils asked answered that always or often they are motivated to study mathematics.

Do you think that you can increase the motivation for studying mathematics by solving practical exercises.
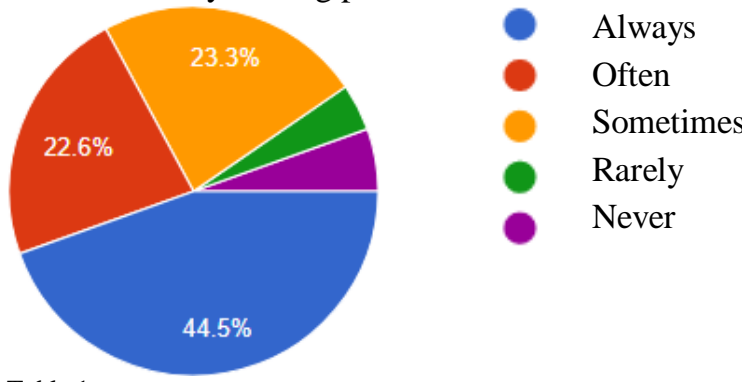

Table 1.

To the question "When you have problems while doing your homework, would you like to have a web site which will give you the steps and help for problems solving" $86 \%$ of the asked pupils said that 
they want and only $5 \%$ that they do not want to have that kind of help.

When you have problems while doing your homework, would you like to have a web site which will give you the steps and help for problems solving.
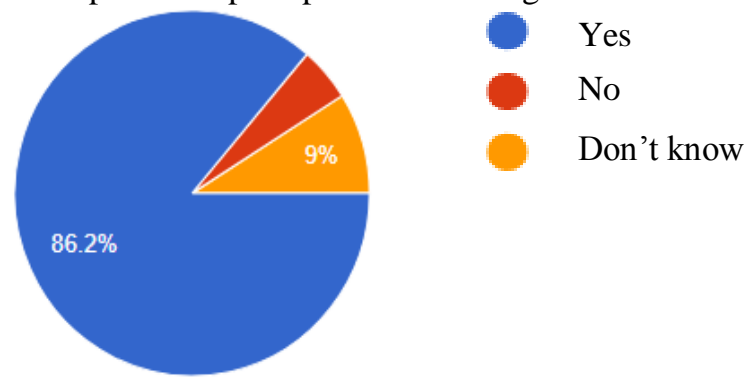

Table 2 .

Summing up the results of this survey justified the beginning of making the web application http://mathlabyrinth.azurewebsites.net [4] on which the exercises related to the real problems are presented, the procedure for their solving and visualization and then its usage in the teaching and also while doing the homework. The web application is free and it can be used with prior registration.

\section{METHODOLOGY FOR MAKING TEXTUAL EXERCISES FROM THE WEB APPLICATION}

Before starting to make the web application it was necessary to choose the exercises and a procedure for their solving.

The exercises that are presented on the web site are from the text books which are used in our country or on the international tests and are related to everyday problems which the pupils can encounter. The exercises are grouped by themes (Picture 1).

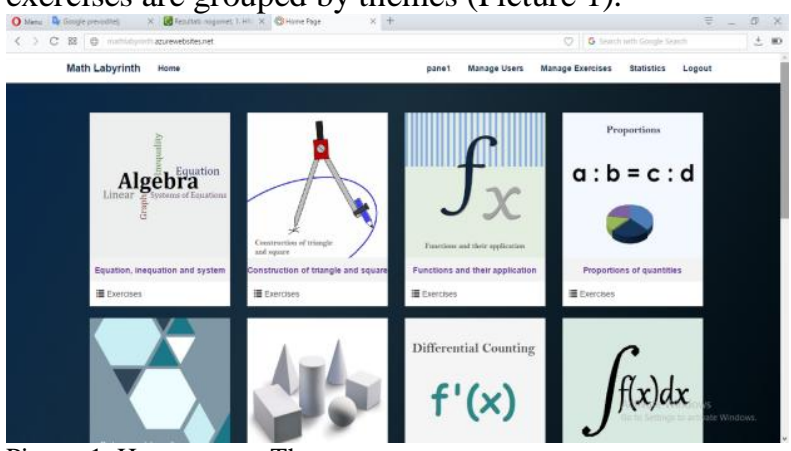

Picture 1. Home page - Themes

While determining the procedure for exercises solving, knowing that they will be solved during lesson and in domestic conditions, a procedure based on Pólya presented in the book "How to solve" has been used [5].

The procedure is based on four principles and they are:

First, understanding the problem
- After understanding you make a plan for solving,

- Implementation of the plan,

- To look at the procedure and the problem solving. Can it be improved and how?

problem

The first principle - Understanding the

"Understanding the problem" is often neglected, as if it is apparent, so it even isn 't mentioned during the mathematics lessons. However, the pupils are often stuck in this step, when they want to solve the exercise alone, simply because they don't fully understand the given problem. In order to fix this sight, Pólya gives the instructions how the teachers can encourage the pupils, with appropriate questions, depending on the situation, such as: What needs to be found or shown? Can you repeat the problem in your own words? Can you make a drawing or a diagram which will help you understanding the problem? Do you understand all the words which are used in the problem presentation? Thus, at the beginning of the exercise, which is presented on the web site, the teacher chooses couple questions with appropriate level of difficulty depending on the age of the pupils, in order to understand the exercise and to know what needs to be calculated.

The second principle - make a plan

According to Pólya it is been mentioned that there are many reasonable ways for problems solving. The skill of choosing the appropriate strategy can be leant best by solving many problems and this should be highlighted to the pupils. Partial list of strategies is: guess and check, elimination of possibilities, use symmetry, think of different cases, use direct thinking, solve equations.

A concrete list of strategies is: look for a model, drawing a picture, use a formula, be creative, use skills and so on.

In the process of choosing the plan and the procedure for solving the exercise it is used free software for visualization of the problems and presentation of different procedures for their solving. It is always mentioned that this is one of the procedures for solving the exercise, that with the pupils`creativity the exercise can be solved differently and much faster.

The third principle - Implementation of the plan

This step is usually easier than making the plan. In fact, all you need is care and patience, considering that they have the needed skills. They should continue with the chosen plan. The author of this step mentions that: if it doesn't work, throw it away and choose another plan. Don't fool yourself; this is the principle how the mathematics is done, even by the professionals.

In this part the teacher describes the steps for calculation of the exercise solution in details. He/ She encourages the pupils that with this procedure the 
problem can be solved. But if they try some other way to solve the problem and it doesn't work, they should throw that plan away and try a new one, without losing hope in the process of the problem solving.

The forth principle - Check/ widen.

Pólya mentions that it can be achieved a lot if you take your time to think and to look back to what you have done, the things that you have done and the ones you haven't. That will allow you to see what strategy to use to solve problems in the future, if they are related to the original problem.

At the end the teacher congratulates them for the successfully finished work and he/ she encourages them to use these principles while solving the other exercises. If they have some new solution and thinking, they should send it to the teacher so that it can be published and shared with the other pupils.

\section{IMPLEMENTATION OF WEB APPLICATION}

Using these principles a web application "Math labyrinth" has been made, where textual exercises related to the real life are set [4].

For each exercise which is set on the web application first there is a preparation using the principles of Pólya and the guidelines which are gained from the survey. (Picture 2)

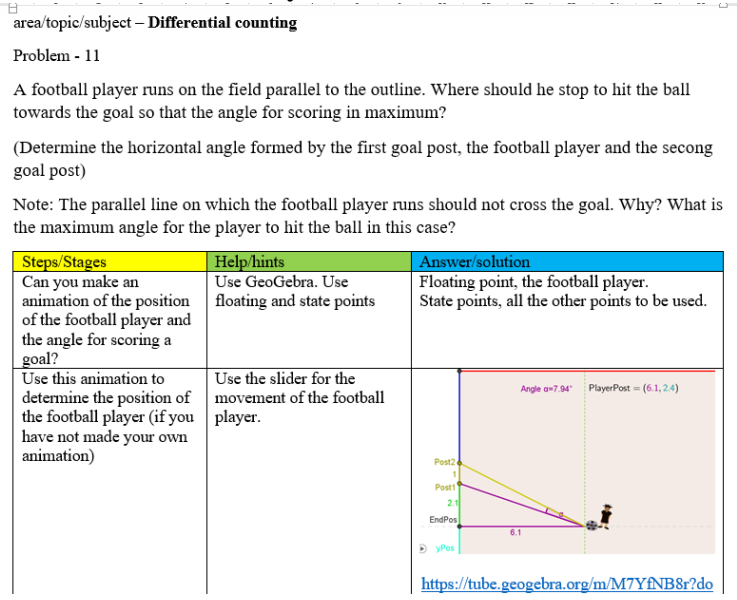

Picture 2. An example of a ready task.

By signing the web site as an administrator (teacher) you can set the exercises. The main menu contains Math Labyrinth-Home, Manage Users, Manage Exercises and Statistics.

Way of setting the exercises.

By choosing the option Manage Exercises, fields for entering the exercise are opened,

In the field Exercise Description, the text of the exercise should be entered, in the field Exercise Name the title of the exercise should be put, and in the field Exercise Topic, from the dropping menu, the theme of the exercise should be chosen (Picture 3 ).

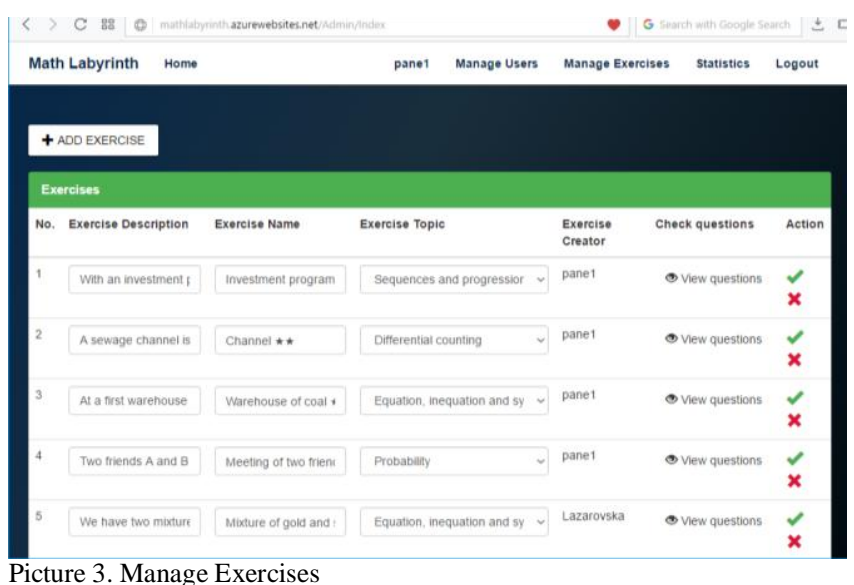

By clicking on View question, you go to the next window where you write Question, Help, Answer and Additional. In each field you can add text or a file by choosing one of the buttons Add/Edit text or Add/Edit file. In the field Question you write the question in Latex. In Help you add some kind of help for the question in order to get to the answer. In Answer you write the answer of the question, picture or link to some applet which is related to the answer. In Additional you add the additional information about the applet construction, the construction of the picture or some other additional information which can be used by the pupils while solving the exercises (Picture 4).

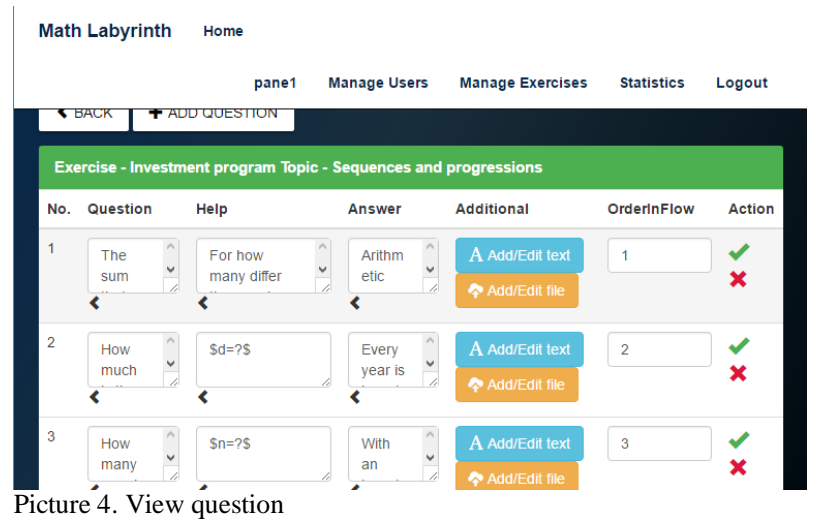

In the field Order in Flow you choose the ordinal number of the question in the exercise and at the end it is recorded.

After you enter all the questions and the answer we go back to the home page and the whole exercise is recorded again.

This is the way in which all exercises are set on the web application.

- How will the pupils use the web application?

By signing the web application as a pupil, each pupil can use the given exercises. The main menu contains: Math Labyrinth Home and Logout (Picture $5)$. 


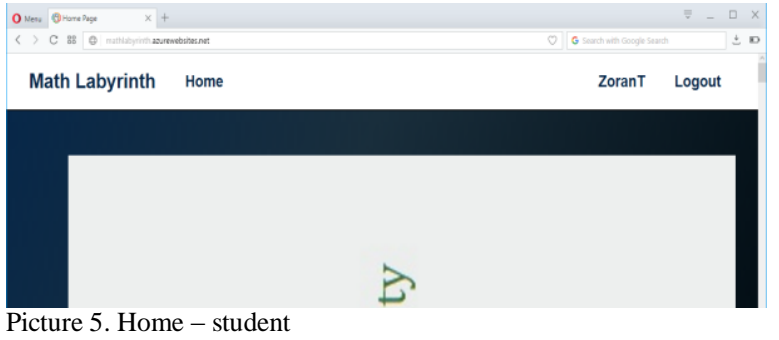

In Home all themes are set. By choosing a theme you go to the exercises which are set in that topic. The pupil can read the titles of the exercises and their content. If the pupil wants to solve some exercise and to see what is its solution, he/ she clicks the button Play in order to begin with the exercise, in other words to start with "the game" in Math Labyrinth. The steps for solving are set in a form of labyrinth, and that's why the entire application is called Math Labyrinth. By clicking the button Play you begin the procedure for solving the exercise. First you open one window, in which you can see the principles of Pólya written and then you choose the work model of the exercise: Test mode- if you only want to use the questions and the help for getting to the solution of the exercise, in other words it only tests you if you can get to the solution or Practice mode- if you want to use the questions, the help and the answers for each question, which will lead to the solution of the exercise (Picture 6).

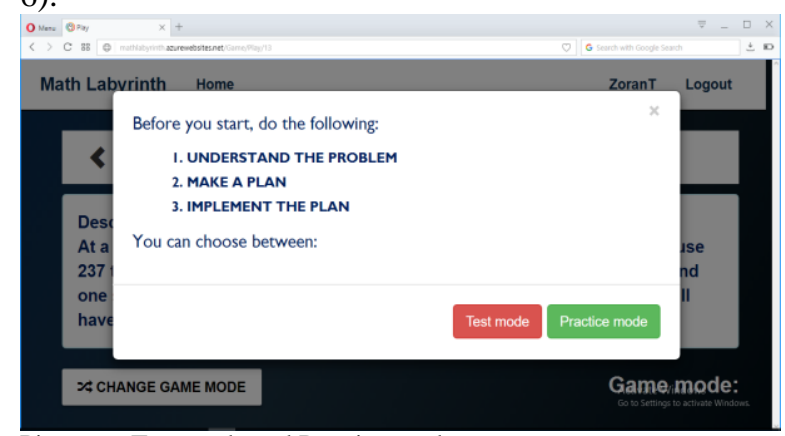

Picture 6. Test mode and Practice mode

By choosing one mode for solving the exercise, a window is showed in which the labyrinth is set and by clicking the button number 1 you begin the procedure of presenting the exercise (Picture 7).

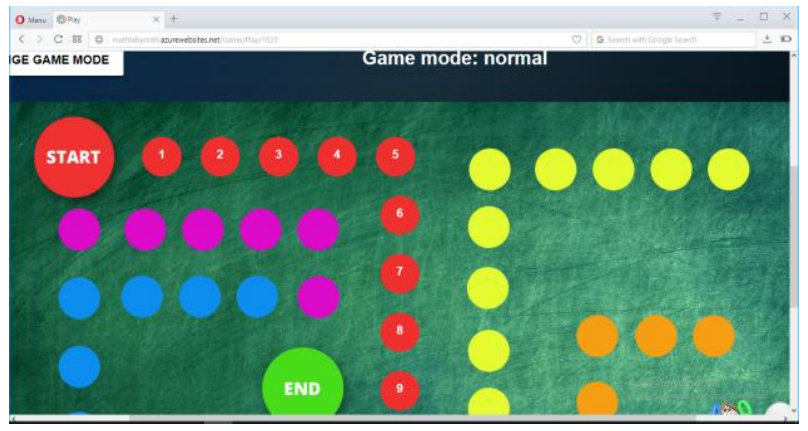

Picture 7. Math Labyrinth

In each step there is only one question which needs to be answered by the pupil, some picture or link to an applet where the pupil should go in order to see the visualization of the exercise or the solution (Picture 8).

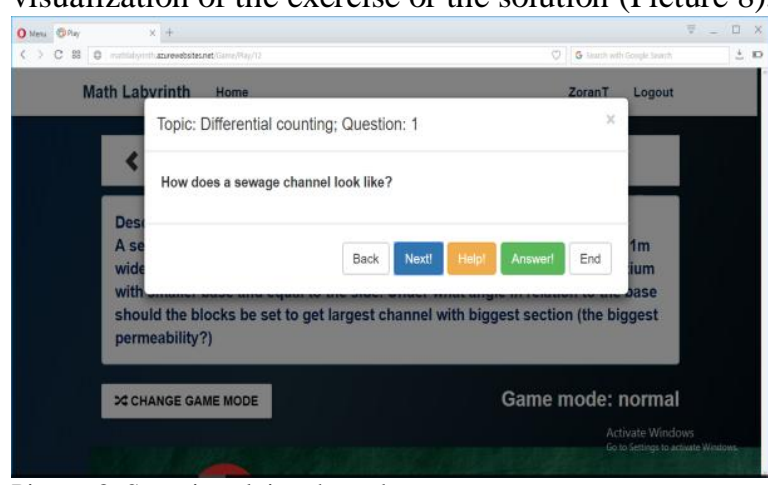

Picture 8. Steps in solving the task

After finishing the procedure for solving the exercise, in other words doing all steps foreseen by the teacher, the pupil gets the solution, and then also a window in which is written congratulations on his/her persistence. Meanwhile it encourages the pupil to try independent solving of the remained exercises.

\section{USE OF THE WEB APPLICATION}

If we are signed as Super Admin, in the space for Statistics we can see how many users are registered on the site, how many of them are pupils and how many teachers.

During the test period, this web site was used by 20 teachers and they all have positive thinking about it, for the way of presenting the exercises and the use of the web site.

In the first year 130 pupils were registered as users of this web site.

The teacher can see which pupils have used this site so far, how long were they on the site and which exercises they solved completely.

One finishing survey was done at the end of the test period.

Some questions from the survey and the given answers:

- To the question "Did the solving of practical exercises increase your motivation for studying mathematics" $75 \%$ of the pupils asked said that their motivation for studying mathematics was increased.

Did the solving of practical exercises increase your motivation for studying mathematics
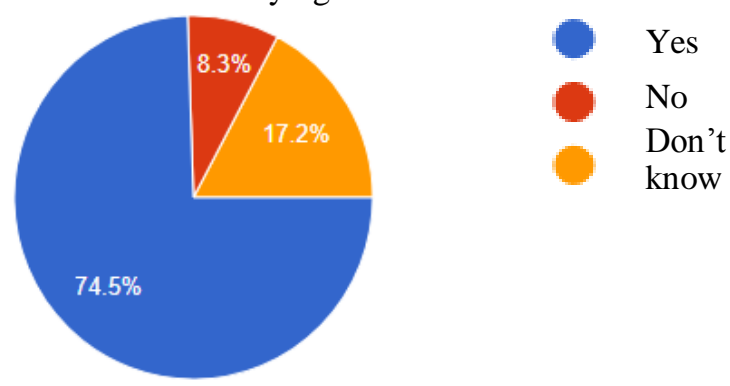

Table 3 . 
- To the question "Did the use of the web site help you while doing your homework?" $71 \%$ said that it always or often helped them while doing their homework.

Did the use of the web site help you while doing your homework?
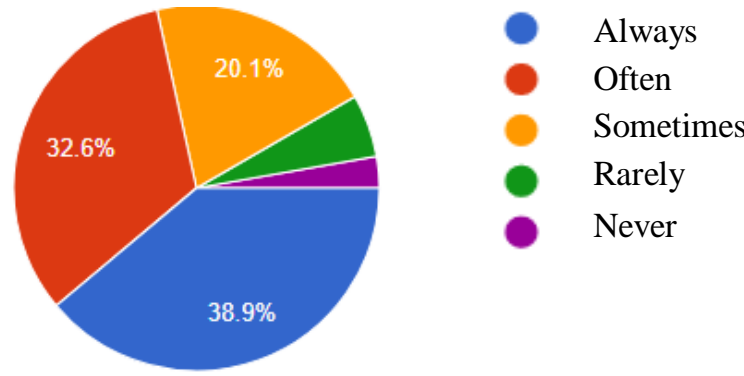

Table 4 .

- To the question "Did the visualization of the exercises and the use of free software help you to understand and to solve the exercises more easily?" $78 \%$ of the pupils said that they always or often helped them while doing their homework.

Did the visualization of the exercises and the use of free software help you to understand and to solve the exercises more easily?
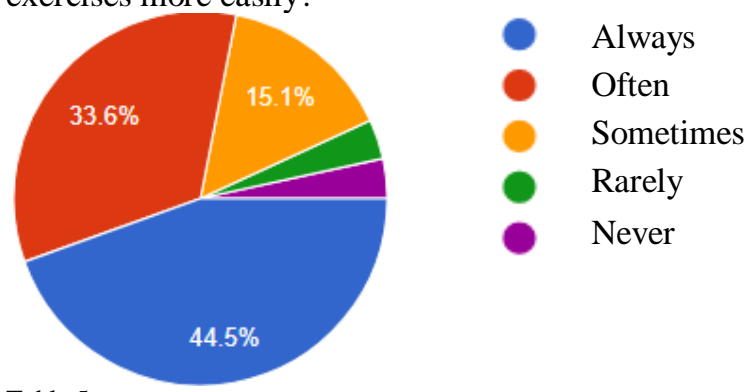

Table 5.

\section{CONCLUSION}

By using the web application and IT in the math teaching, while solving exercises and their visualization, the motivation of the pupils from the Gymnasium for studying mathematics has been increased. A lot of pupils are satisfied that they get to the solution of the exercises in domestic conditions with the help of the visualization and the help of the website.

Thus we encourage you to use this application and other web applications or free software while solving the math problems, because we will have pupils who will be motivated to study mathematics and to achieve better results.

\section{REFERENCES}

[1] Stojanovska L. Trifunov Z. (2010) „Constructing and Exploring Triangles with GeoGebra“. Anale Seria Informatica, Vol VIII, Fac.2, România, pp. 45-54

[2] J.M. V. Sarac, T. Atanasova-Pacemska, Z. Trifunov, ELECTRONIC TESTS IN HIGH EDUCATIONOPPORTUNITIES AND CHALANGES, International Conference on Information Technology and Development of Education. University of Novi Sad, Technical Faculty „Mihajlo Pupin”, Zrenjanin, Republic of Serbia, pp. 68-72. ISBN 978-86-7672-225-9

[3]Анкета:https://docs.google.com/forms/d/1Ry-OYVmBx8caWRaRMo-8g5fkZ3J_CBxuMTDDGVRxko/edit

[4] http://mathlabyrinth.azurewebsites.net/

[5] „How to solve it“", Pólya

[6]http://www.oecdilibrary.org/docserver/download/9816061e.pdf?e xpires $=1500114561 \&$ id=id\&accname=guest \&checksum $=3$ A7 1182A997F99384D8B918FBD3C1C9E

[7] Trifunov Z., Karamazova E., ... (2015) „Introduction of discrete and continuous random variable“. LAP LAMBERT Academic Publishing. ISBN: 978-3-659-79405-6 